\title{
CLINICO-EPIDEMIOLOGICAL PROFILE OF VERRUCAE: A HOSPITAL BASED STUDY
}

\section{Dermatology}

Dr. Sandeep Sidhu

Assistant Professor, Department of Dermatology, Venereology and Leprosy, Government Medical College, Circular road, Amritsar, Punjab 143001.

\section{Dr. Tejinder kaur*}

Professor and Head, Department of Dermatology, Venereology and Leprosy, Government Medical College, Circular road, Amritsar, Punjab 143001.*Corresponding Author

Junior Resident, Department of Dermatology, Venereology and Leprosy, Government Medical College, Circular road, Amritsar, Punjab 143001.

\section{ABSTRACT}

AIM: To study the clinical and epidemiological aspects of verrucae in relation to age, sex, occupation, associated symptoms and sites involved. MATERIAL AND METHOD: The retrospective study was conducted in a sample of 60 clinically diagnosed cases of verrucae who attended the outpatient Department of Dermatology and Venereology ,Government Medical College, Amritsar over a span of six months. RESULTS: The clinical characteristics of different types of verrucae were studied in 60 patients from September 2019 to February 2020, out of which 41 were male and 19 were female. The majority of patients belonged to the age group of 11 to 30 years $(48 \%)$. The most common occupational group involved were students $(46 \%)$ followed by office workers $(35 \%)$. The presenting complaint of $82 \%$ of patients was a cosmetic concern only while $8 \%$ patients presented with pain mostly seen in the verrucae plantaris. CONCLUSION: In this study, male patients had a higher prevalence of verrucae but facial verrucae were the more commonly seen in females. The majority of the verrucae were asymptomatic and patients only had a cosmetic concern.

\section{KEYWORDS}

Verrucae, Human Papilloma Virus

\section{INTRODUCTION:}

Verrucae are benign proliferative lesions over the skin and are caused by various strains of the Human Papillomavirus (HPV). Papillomaviruses are small deoxyribonucleic acid (DNA) virus and about 120 different types of HPVs have been fully characterized. There are a large number of additional types whose complete genetic sequence has not been obtained indicating the presence of about 200 HPV genotypes [1]

Humans are the primary reservoir of the virus. HPV infects the basal keratinocytes, where it can survive for months to years $[2,3,4]$. There is no systemic dissemination or viraemic phase to HPV infection. Transmission is either by direct or indirect contact i.e. autoinoculation. Indirect contact can be via fomites, such as flooring, socks, shoes, towels, and sports equipment $[5,6]$. Pre-existent microtrauma is the predisposing factor that allows entry of the virus [7-11]. The virus binds with cellular receptors in the basal epithelium and is subsequently taken up by the now-infected cell. The incidence of warts increases during the school years to reach a peak in adolescence and early adulthood $[12,13]$. Infected person develops specific protective immunity against the virus thus reinfection with the same HPV type is uncommon [14]. Langerhans' cell numbers are reduced within verrucae and $\mathrm{T}$ lymphocytes are rare within the epidermal compartment leading to an apparent failure of the immune system in otherwise healthy individuals and taking months and years to clear them $[1,15]$. Warts not responding even after five treatments over the period of six months are taken as recalcitrant warts [16]. Severe recalcitrant lesions usually raise the suspicion of immune defects in the individuals especially if occurring with other infections, atopy, autoimmunity, or malignancy[17].They can appear in various morphological types on different sites of the body which include verrucae vulgaris, verrucae plana, myrmecia, verrucae plantaris, filiform verrucae, periungual verrucae, anogenital verrucae, oral, respiratory papillomas. Common verrucae are exophytic, hyperkeratotic, dome-shaped papules or plaques that are typically associated with HPV-1, 2, 4, 27 or 57. They are most frequently located on the sites prone to trauma such as dorsal surfaces of the hands and fingers, knees or elbows [18].Verrucae plana are skin coloured or brownish papules, usually present in groups. They are most commonly seen over sun-exposed areas especially the face. These lesions tend to spread with shaving and other procedures due to autoinoculation and koebnerization. Verrucae plantaris are hyperkeratinized papules seen on the plantar aspect of the foot. They are commonly called seed verrucae as the blood vessels appears like black dots in the lesions resembling seeds. Verrucae plantaris tend to develop at areas of increased pressure on the sole, including the heel and metatarsal heads $[4,7,9]$. Filiform verrucae are finger-like projections that protrude from the skin and often appear on eyelids or around the oral cavity.

HPV is shed via desquamated epithelial cells from the established verrucae which subsequently infect other sites and hosts. Various treatment options are currently available but these lesions are usually resistant to treatment and tend to reoccur frequently. Thus primary prevention is very important and to prevent the cycle of transmission we have to identify the high risk groups and other epidemiological aspects. We have undertaken this study to assess the clinicepidemiological aspects of different types of verrucae in patients visiting dermatology OPD at Government Medical College, Amritsar.

\section{MATERIALAND METHODS:}

The data was collected from September 2019 to February 2020. Patients of different age groups, diagnosed as a case of verrucae who presented to the dermatology OPD at GNDH Amritsar and were on regular follow up were included.

A detailed history pertaining to onset, associated symptoms, duration and progression of lesions were taken and recorded in preformed performa. Complete physical examination was carried out in all the cases along with the local examination of the lesions with particular attention to the type, distribution of lesions, number of lesions

RESULTS: Sixty clinically diagnosed cases of verrucae were studied. In the study, various morphological variants of viral verrucae were seen among all the age groups of both the sexes. The most common being verrucae plana $(37 \%)$ followed by verruca vulgaris $(28 \%)$ and filiform verrucae $(25 \%)$. Verrucae plantaris was seen in $7 \%$ and periungal in $3 \%$ of cases. Two patients had both verruca vulgaris as well as verrucae plana.

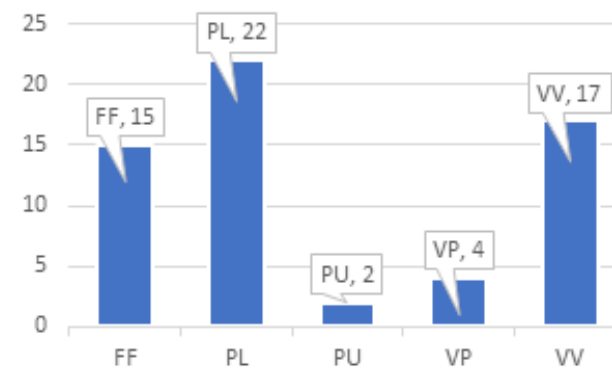

Figure 1: Types of verrucae (VV: Verruca vulgaris; VP: Verrucae plantaris;PL:Plane; FF: filiform ; PU: Periungual) 
Face including forehead, nose, eyelids, cheeks, chin was involved in $60 \%$ of cases and the Forehead was the most commonly affected area of the face.

The next common site involved was the upper $\operatorname{limb}(27 \%)$ which included hands, forearm and arm, two cases of periungal wart were also there. Right upper limb was more involved as compared to the left. Verrucae on the lower limb were seen in $11 \%$ of patients. Only $2 \%$ of cases had verrucae over the trunk.

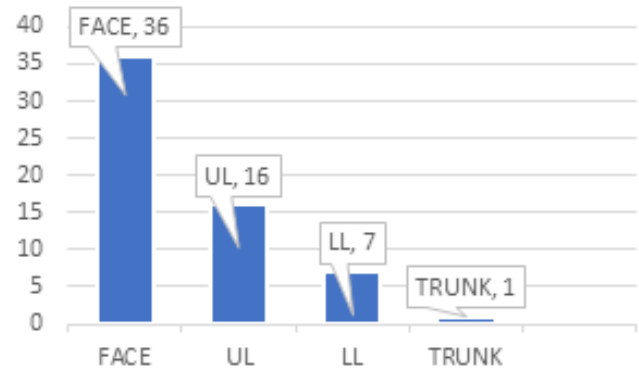

Figure:2:Sites of involvement

Most of the verrucae had a duration of less than six months (42\%) and $25 \%$ of the verrucae had duration ranging from 6 months to 12 months. Eight patients had lesions from more than 18 months, among them a 65 -year-old male had lesions from 6 years. Two male students age 10 years and 12 years, also had lesions from more than 2 years.

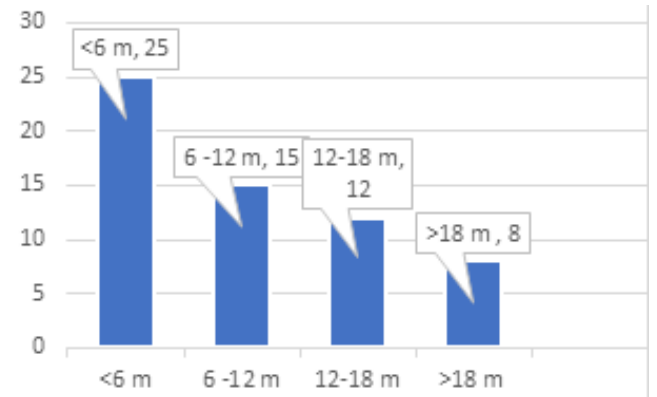

Figure:3 Duration of lesions

These lesions were seen in both sexes with age varying from 3 years to 70 years. Correlation of age with the clinical types of verrucae revealed that $76 \%$ of the patients belonged to 2 nd to 4 th decades, maximum patients $(48 \%)$ belonged to 11 to 30 years of age.

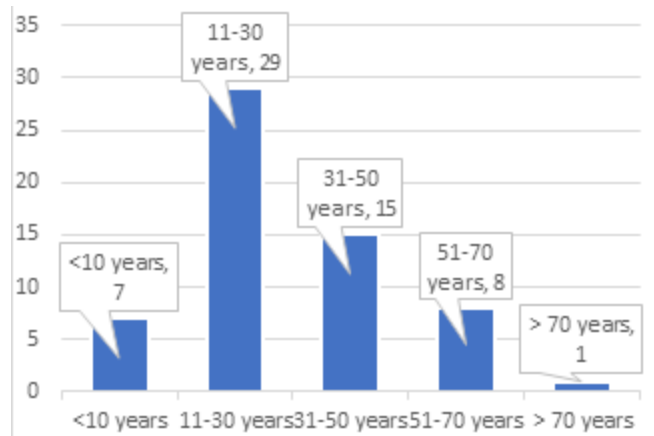

\section{Figure :4 Age distribution of verrucae}

Verrucae plantaris were equally distributed among both males and females. All other forms of verrucae were more common among male patients belonging to various decades of life. Male to female ratio was 2.1:1

\begin{tabular}{|l|l|l|l|}
\hline Type & Male & Female & Total \\
\hline VV & 14 & 3 & 17 \\
\hline PL & 12 & 10 & 22 \\
\hline VP & 2 & 2 & 4 \\
\hline PU & 2 & 0 & 2 \\
\hline FF & 11 & 4 & 15 \\
\hline & 41 & 19 & 60 \\
\hline
\end{tabular}

Table:1 Sex distribution of verrucae ( VV: Verruca vulgaris; VP:
Verrucae plantaris;PL:Plane; FF: filiform; PU: Periungual)

Out of 60 patients, $42(72 \%)$ presented with less than five verrucae and $14 \%$ had five to ten lesions and more than 10 lesions over the body.

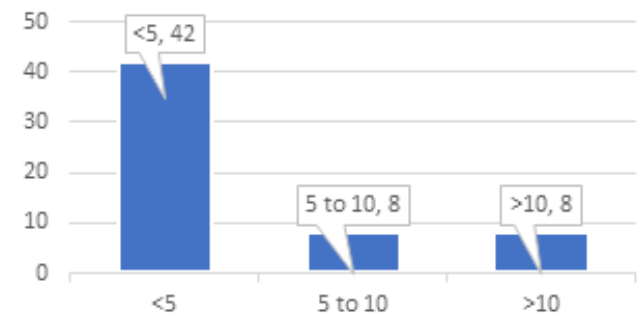

Figure :5 Number of verrucae

The most common concern was cosmetic, seen in $82 \%$ of the patients. The itching was reported by $10 \%$ of the patients whereas only $8 \%$ of patients complained of pain over the lesion. All the patients of plantar verrucae over the soles presented with pain

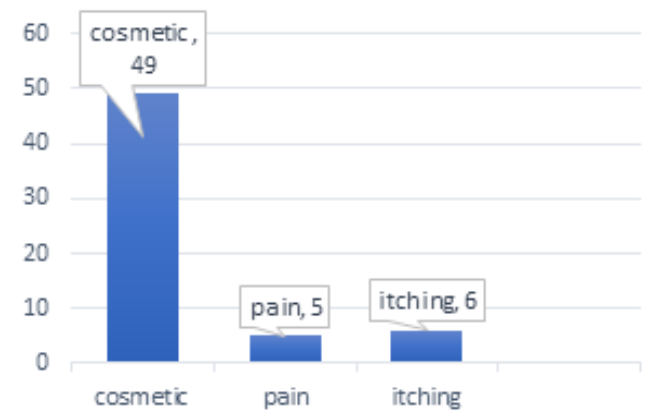

Figure :6Associated complaints and sypmtoms

Students were the most affected group ( $46 \%$ ) followed by office workers ( $35 \%$ ). Of the total patients, $17 \%$ were housewives and $2 \%$ were retired employees.

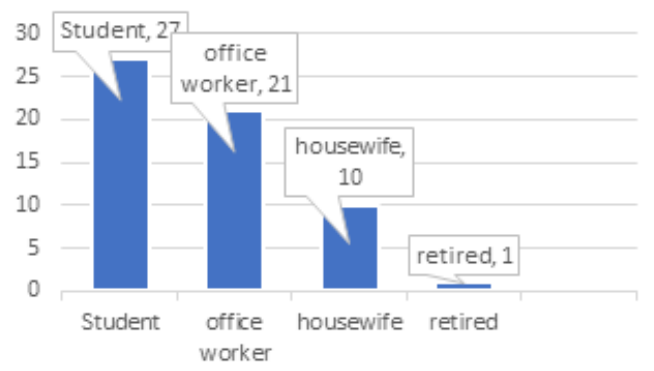

Figure:7 Distribution in relation to occupation

\section{DISCUSSION:}

HPV can cause both genital and non-genital verrucae which can present in various clinic-morphological forms. In our study verrucae plana $(37 \%)$ followed by Verruca vulgaris $(28 \%)$ were found to be the most common clinical type of verrucae. However, in a clinicoepidemiologic study conducted by Ghadgepatil SS et.al found verruca vulgaris $(42 \%)$ as the most common non-genital warts followed by palmoplantar and plane warts [17]

Facial warts were seen in $60 \%$ of total patients and $73 \%$ of total female patients, involving the forehead, eyebrows, eyelids and cheeks, chin. Frequent involvement of the face is probably attributable to the increased cosmetic procedures like waxing, threading, facials, shaving, and so forth. These procedures lead to autoinoculation and koebnerization thus increasing the chances of development of verrucae.

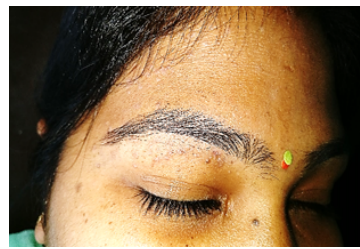

Figure:8: Verrucae plana around eyebrow and over forehead 
The next commonly involved site was upper-limb (27\%), more in male patients as compared to females, which could be related to more workrelated trauma in males. Theng et al. in a study reported that $39 \%$ of the subjects had upper limb involvement which does not match with our findings [18]. Laxmisha et al and Kushwaha et al also found most common sites for common warts were on the dorsum of hands.

In $42 \%$ of patients, lesions were of duration less than 6 months, similar findings were observed by Ghadgepatil SS et.al in their study which showed that $43 \%$ of patients had warts for 4-6 months [17]. We also observed that six patients had progressive and symptomatic verrucae for more than two years out of which two students had periungual verrucae over the right index finger and right great toe.

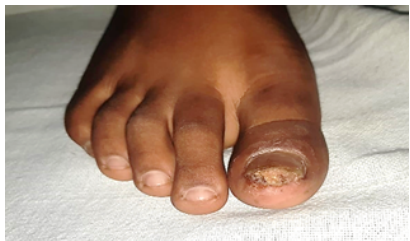

Figure: 9 Verrucae over great toe

These lesions were persistent despite all treatments and this could be due to the repeated trauma over the lesion while playing which causes disruption of the epithelial barrier and allowed reinfection and autoinoculation. A study by Singh s has shown that $65 \%$ to $78 \%$ of cutaneous verrucae have been shown to regress within 2 years [19]. In persons older than 12 years, the rate of spontaneous regression significantly decreases $[20,21]$. Although we don't have any immunocompromised patient in the study we had a sixty-five year male patient with filiform verrucae over the right index finger for 3 years. His lesions were not regressing despite treatment which was most probably due to reduced immunity with age.

Verrucae were most commonly seen in patients belonging to the 2nd and 3 rd decade of life. As this age group includes adolescents and younger individuals who tend to experiment with new procedures, that could make them prone to get infected. A similar study was conducted by Berth-Jones and Hutchinson, they found that $54 \%$ of patients were in the age group of 11-25 years[22]. Increased prevalence of warts among the young population especially common and plantar warts could be due to increased propensity to trauma facilitated-inoculation as well as decreased immunity

Males were twice the number of females probably due to their increased outdoor activities and increased cosmetic awareness among males. In today's world, where physical appearance is given huge importance both males and females have become much more concerned about their looks. Similar findings were observed by Laxmisha et al with a male to female ratio of 1.8:1[23]. It was also found that male patients sought medical advice with as early as 2 weeks of the duration of warts as compared to female patients who visited the hospital after 2 months of the appearance of lesions. This clearly shows the delay in seeking care by female patients which could be a result of the dependency of majority of the women in our study on family members to visit the health centre.

Only $8 \%$ of patients had pain over the verrucae and $82 \%$ were asymptomatic had only cosmetic concern. These findings were in accordance with a study conducted by Vaishnavi Gopal [24]. All the patients with plantar verrucae over the soles complained of pain which could be because of the pressure while walking or running over the lesion or due to local trauma.

More than ten lesions were seen in $63 \%$ of patients having flat verrucae, this could be linked to the mode of infection.

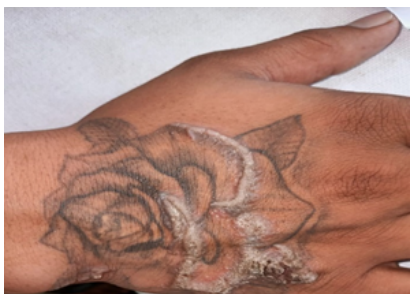

Figure:10 Verrucae Vulgaris with Koebnerization after tattooing.
Koebnerization is a well-known phenomenon with verruca plana. In a study by Vaishali Masatkar et al koebnerization was seen in $61(63.5 \%)$ patients [25]. As discussed earlier cosmetic procedures could be the reason for the prevalence of flat verrucae especially over the face in females. Infected persons doing these procedures or infected threads or blade may inoculate viral particles.

Campion has mentioned in his study that verrucae showed an increase during the school years, peaking within $12-16$ years [26]. We found that students $(46 \%)$ were the most commonly affected group followed by office workers. The higher incidence among students may be due to their increased susceptibility during their manual/ physical activities thus higher risk of damaging the stratum corneum that serves as the entry for HPV. Office workers (35\%) are the second most commonly affected group as they are more exposed to fomites like paper, pens, clips, etc at their workplace thus making them more vulnerable to get verrucae. Although no studies have been done in this aspect but the use of biometric attendance at offices has further increased the chances of the spread of infection. The role of fomites in spreading infection at public places has been studied by Bruggink SC et al and Johnson LW et al in their studies[5,6]. Housewives have a higher propensity to sustain minor cuts while doing household work especially kitchen work and cracking of soles while walking barefoot at home, that could explain the occurrence of verrucae among female. Although the older age group have reduced immunity and have greater chances of acquiring verrucae but in our study we observed older patients have very less prevalence. This is could be explained by the fact that the majority of verrucae are asymptomatic and patients tend to ignore these lesions and rarely consult dermatologists until or unless they become symptomatic.

\section{CONCLUSION:}

We found that flat verrucae were the most common clinical presentation. Overall verrucae were most prevalent in the 2 nd decade of life. Male students were most susceptible to acquiring cutaneous verrucae that may be because of increased chances of contact with multiple individuals in schools and colleges. Also they tend to ignore minor injuries that could act as a portal of infection of the virus. Facial warts were more prevalent among female patients, probably due to increased cosmetic procedures like facials, shaving, threading, trimming etc. Therefore, people should be made aware about the route of the spread of verrucae to prevent their spread. Saloon owners should follow strict cleaning and sanitizing guidelines. They can play a very important role in controlling the spread of verrucae. As patients with chronic illness such as infections, atopy, autoimmunity, or malignancy have reduced immunity, they are at greater risk of developing cutaneous warts, so the role of HPV vaccination in such individuals should be further evaluated as it can provide a quicker, cheaper and safer method of prevention of warts .Since studies of clinicoepidemiological correlation of warts are sparse, variously designed studies are required to validate some of these correlations found in our study..

\section{REFERENCES:}

Sterling JC Viral Infections. In. Burns T, Brethnach S, Cox N, Griffiths C, editors. Rooks Textbook of Dermatology. 8th ed. West Sussex: Willey Blackwell: 2010:33-59. Gearhart PA, Randall TC, Buckley RM, Higgins RV. Human papillomavirus. Medscape website. http://emedicine.medscape.com/article/219110-overview. Updated January 5 , 2017. Accessed December 5, 2017.4

3. Barna Z,Kadar M. The risk of contracting infectious diseases in public swimming pools a review. Ann Ist Super Sanita. 2012;48(4):374-386

4. Plantar warts. The American College of Foot \& Ankle Orthopedics \& Medicine website. http://www.acfaom.org/information-for-patients/ common-conditions/plantar-warts. Accessed July 21,2016

5. Bruggink SC, Eekhof JA, Egberts PF, van Blijswijk SC, Assendelft WJ, Gussekloo J. Warts transmitted in families and schools: a prospective cohort. Pediatrics. Warts transmitted in families and schools: a prot

6. Johnson LW. Communal showers and the risk of plantar warts. J Fam Pract. 1995;40(2):136-138. 24. Barna Z, Kádár M. The risk of contracting infectious diseases in public swimming pools: a review. Ann Ist Super Sanità. 2012;48(4):374-386.

7. Sudhakar GK, Pai V, Pai A, Kamath V. Therapeutic approaches in the management of plantar warts by human papillomaviruses: a review. Asian J Biomed Pharm Sci 2013;3(26): 1 -4.

8. Lipke MM. An armamentarium of wart treatments. Clin Med Res. 2006;4(4);273-293.

9. Cubie HA. Disease associated with human papillomavirus infection. Virol J. 2013;445:21-34

10. Silverberg JI, Silverberg NB. Childhood atopic dermatitis and warts are associated with increased risk of infection: a US population-based study. J Allergy Clin Immunol. 2014;133(4):1041-1047

11. Longworth MS, Laimins LA. Pathogenesis of human papillomavirus in differentiating epithelia. Microbiol Mol Biol Rev. 2004;68:362-372.

12. Barr A, Coles RB. Plantar warts. A statistical survey. Trans St Johns Hosp Dermatol Soc. $1966 ; 52: 226-38$

13. Kilkenny M, Marks R. The descriptive epidemiology of warts in the community. Australas J Dermatol. 1996;37:80-6.

14. De Koning MN, ter Schegget J, Eekhof JA, Kamp M, Kleter B, Gussekloo J, et al. 
Evaluation of a novel broad-spectrum PCR-multiplex genotyping assay for identification of cutaneous wart-associated human papillomavirus types. J Clin Microbiol. 2010;48:1706-11.

15. Chardonnet Y, Viac J, Thivolet J. Langerhans cells in human warts. Br J Dermatol. 1986;115:669-75.

16. Leung L. Recalcitrant nongenital warts. Aust Fam Physician. 2011;40:40-2

17. Leiding JW, Holland SM. Warts and all: human papillomavirus in primary immunodeficiencies. J Allergy Clin Immunol. 2012;130(5):1030-1048. doi:10.1016/j.jaci.2012.07.049

18. Kirnbauer R, Lenz P. Human Papailloma Virus. In: Bolognia JL, Jorrizo JL, Schaffer JV, editors. Dermatology. 3rd edition. China: Elsevier; 2012: 1303-1319.

19. Ghadgepatil SS, Gupta S, Sharma YK. Clinicoepidemiological study of different types of warts. Dermatol Res Pract. 2016;2016:7989817. doi: 10.1155/2016/7989817

20. T. S. C. Theng, B. K. Goh, W. S. Chong, Y. C. Chan, and Y. C. Giam, "Viral warts in children seen at a tertiary referral centre," Annals of the Academy of Medicine Singapore, vol. 33, no. 1, pp. 53-56,2004

21. Singh S, Chouhan K, Gupta S. Intralesional immunotherapy with killed Mycobacterium indicus pranii vaccine for the treatment of extensive cutaneous warts. Indian J Dermatol Venereol Leprol. 2014;80 (6):509-514. doi:10.4103/0378-6323.144145

22. Bavinck JNB, Eekhof JAH, Bruggink SC. Treatments for common and plantar wart. BMJ. 2011;342:d3119. doi:10.1136/bmj.d3119

23. Bruggink SC, Gussekloo J, Berger MY, et al. Cryotherapy with liquid nitrogen versus topical salicylic acid application for cutaneous warts in primary care: randomized topical salicylic acid application for cutaneous warts in primary care: ran
controlled trial. CMAJ. 2010;182 (15):1624-1630. doi:10.1503/cmaj.092194

24. J. Berth-Jones and P. E. Hutchinson, "Modern treatment of warts: cure rates at 3 and 6 months," British Journal of Dermatology, vol. 127, no. 3, pp. 262-265, 1992.

25. Laxmisha C, Thappa DM, Jaisankar TJ. Viral wartsA clinico-epidemiological study. Indian J Dermatol. 2003;48:142

26. Common warts revisited: a clinical study:V Gopal, MM Shenoy, M Pinto - International Journal of Research ...,2017

27. Clinicoepidemiologic study of verruca plana at a tertiary care center :V Masatkar, LK Gupta, AK Khare, S Mehta... - Indian Journal of ..., 2018 - ijdvl.com

28. M. J. Campion, "Clinical manifestations and natural history of genital human papillomavirus infection," Obstetrics and Gynecology Clinics of North America, vol. 14, no. 2, pp. 363-388, 1987 . 